\title{
Modelling estuarine Crustacea population fluctuations in response to physico-chemical trends
}

\author{
Martin J. Attrill ${ }^{1, *}$, Michael Power ${ }^{2}$, R. Myles Thomas ${ }^{3}$ \\ ${ }^{1}$ Benthic Ecology Research Group, Plymouth Environmental Research Centre, Department of Biological Sciences, \\ University of Plymouth, Drake Circus, Plymouth, Devon PL4 8AA, United Kingdom \\ ${ }^{2}$ Department of Agricultural Economics, University of Manitoba, Winnipeg, Manitoba R3T 2N2, Canada \\ ${ }^{3}$ Environment Agency, Apollo Court, 2 Bishops Square Business Park, St. Albans Road West, Hatrield, Hertiordshire \\ AL10 9EX, United Kingdom
}

\begin{abstract}
Regular samples (generally every 2 wk) of 6 estuarine crustacean species, Carcinus maenas, Liocarcinus holsatus, Crangon crangon, Palaemon longirostris, Palaemon serratus and Gammarus spp. (mainly G. zaddachi), were taken over a 12 yr period from the cooling water intake screens of West Thurrock power station on the Thames estuary, UK. Additionally, comparative data sets for abiotic variables (freshwater flow, salinity, temperature, dissolved oxygen, $\mathrm{pH}$, suspended solids, total nitrogen) were collected for the same time period. The comprehensive nature of the time series, and accompanying suite of variables, allowed the construction of statistical models for the trends in population abundance of the 6 species using multiple linear regression techniques. Statistically significant models were constructed for C. maenas, C. crangon and Gammarus spp., accurately predicting annual, and longer term, fluctuations in abundance. All models had strong seasonal components, although for $C$. maenas temperature was the only physico-chemical variable with significant explanatory power The importance of temperature as a controlling variable for the species was reinforced by the inclusion of an instrumental variable to simulate a threshold temperature for foraging activity. The optimal value was found to be $8^{\circ} \mathrm{C}$. C. crangon was found to be positively correlated with dissolved oxygen, but showed a slight decline in abundance over the time period. There was no significant relationship with either salinity or temperature, variables previously suggested as being important. Gammarus spp. abundance had 2 significant explanatory variables (temperature and salinity) but also demonstrated a large decrease in population size with time. $L$. holsatus and $P$. serratus are summer-occurring species, so were recorded too infrequently to adequately capture seasonal dynamics. Despite the long time series, no significant model was possible for $P$. longirostris abundance (non-normal residuals), which has been suggested previously as having a strong relationship with salinity. The results of the study provide the first significant multiple linear regression models that accurately predict estuarine crustacean abundance. Whilst these models are useful for helping to understand variability in the Thames, it will be interesting to determine whether populations in other estuaries demonstrate relationships with similar suites of physico-chemical parameters.
\end{abstract}

KEY WORDS: Thames Carcinus maenas. Crangon crangon Gammarusspp. Palaemon spp. Temporal trends · Models · Temperature - Salinity - Oxygen

\section{INTRODUCTION}

Continuous long-term time series of biological data (>10 yr) have been recognised as being extremely important as aids for understanding the functioning of ecosystems (Callahan 1984) and fluctuations within communities and populations (Coull 1986). They are

•E-mail: mattrill@plymouth.ac.uk also required in order to estimate natural variation in undisturbed systems and interpret long-term effects on these systems (Rhoads \& Germano 1986), as shorter data sets may provide misleading explanations of observed fluctuations (Gray \& Christie 1983, Bourcier 1996). However, despite their value, such data sets are rare, particularly from estuarine and coastal systems (Wolfe et al. 1987), due mainly to logistical and financial constraints. 
The application of statistical techniques to the analysis of such ecological time series is even more uncommon (Jassby \& Powell 1990), despite the fact that time series analysis is a well-developed branch of statistics (e.g. see Wei 1990). This is mainly due to the requirements that the observed measurements should be equally spaced with no missing values (Abraham \& Ledolter 1983, Champely \& Doledec 1997) and that a large number of samples are required (Jassby \& Powell 1990). In addition, a suite of identically matched environmental variables are necessary if statistically significant conclusions on possible controlling factors are to be generated (Champely \& Doledec 1997). The majority of long-term benthic data sets reported in the literature, whilst being of high descriptive value, are reliant on either annual (e.g. Pearson 1975, 1982), bi-annual (e.g. Buchanan \& Moore 1986) or intermittent (e.g. LópezJamar et al. 1995) sampling, which provides a limited number of total samples with matching environmental variables that can be used in any time series model. Coull (1986) stated that the construction of such models, which would allow some predictive ability, should be one of the goals of long-term ecological research.

Attrill \& Thomas (1996) published patterns of invertebrate abundance in the Thames estuary,UK, from $>300$ samples taken regularly over a $16 \mathrm{yr}$ period. The trends in biota were compared with patterns of 3 physicochemical variables (salinity, flow and temperature). However, the paper was a descriptive account of population cycles and no attempt was made to statistically relate the biotic patterns to the physico-chemical data presented, beyond inferences from visually comparing the 2 distributions. Additionally, the suite of possible abiotic controlling factors was comparatively small.

Statistical models are one of the few ways in which systematic analysis of the implications of change in complex systems can be completed (Power 1997). The aim of this paper is to apply such modelling techniques to the analysis oi a comprehensive data set available for the Thames estuary as a means of investigating functional relationships between estuarine crustacean abundance and a range of abiotic variables. Rather than providing purely mechanistic explanations of trends, the analysis seeks to provide, for the first time, a set of statistically valid, multiple linear regression models that are predictive of observed trends in abundance for a set of estuarine Crustacea.

\section{MATERIAL AND METHOD}

Sampling methodology. Samples of Crustacea were taken from the Thames estuary, UK, using the cooling water intake screens of National Power's West Thurrock power station, located on the north bank of the mid-estuary. The site was extensively used to monitor the populations of fish and invertebrates returning to the Thames following its rehabilitation (e.g. Huddart \& Arthur 1971a, Andrews \& Rickard 1980) until the closure of the station in 1993.

Sample methodology was outlined in Attrill \& Thomas (1996) and fully described in Thomas (1998). In summary, Crustacea entering the power station through the cooling water system were removed using rotating band screens and entrapped in nets below the outflow system. These nets were emptied every 30 min and the organisms present identified and enumerated. For temporal comparison, the total catch over a 4 h survey period was pooled and data converted to number of individuals per 500 million litres of water filtered (see Attrill \& Thomas [1996] for conversion equation).

Surveys were repeated every $2 \mathrm{wk}$ at spring tide between 1977 and 1992 inclusive, giving a continual data set for a 16 yr period. However, the period 1989 to 1992 was atypical due to the drought conditions prevailing in the region (Attrill et al. 1996). Low freshwater flows resulting from increased water abstraction from the Thames had significant effects on the measured concentrations of heavy metals, e.g. lead, in the estuary (Power et al. 1999) and have been demonstrated to hold significant implications for invertebrate community structure (Attrill et al. 1996). As a result of the probable confounding effects of drought, analyses in this paper were restricted to the 12 yr pre-drought period from 1977 to 1988 . Sample dates for the period were converted to a time index variable (weeks) measured from January 1, 1977.

Daily flow rates of freshwater into the estuary from the river Thames were measured by a fixed gauging station. Water quality parameters were obtained during water analysis runs by the National Rivers Authority (now Environment Agency) sampling vessel along the length of the estuary. Sampling was completed throughout the year at varying intervals, increasing in frequency during summer as a result of concerns about seasonal changes in water quality. The mean time between samples was $2.7 \mathrm{wk}$, with $84 \%$ of all samples being separated by between 3.0 wk or less. Minimum and maximum times between sample dates were 0.7 and $14.9 \mathrm{wk}$ respectively. The latter occurred in the winter of 1988 coincident with the reduction in winter quality sampling frequency for the period 1986 to 1988. All measurements utilised here correspond to those for the zone off West Thurrock power station. The determinants available over the time period of the study are listed in Table 1, together with the reference for the relevant analytical methodology. Salinity was mid-tide corrected to allow valid temporal comparisons. Other determinants (e.g. biochemical oxygen demand [BOD], phosphate, chlorophyll) did not have a sufficient time series to be included in models. 
Table 1. List of considered model variables, together with reference for the relevant analytical method where appropriate

\begin{tabular}{|c|c|}
\hline Parameter & Reference \\
\hline Freshwater flow & $\begin{array}{l}\mathrm{n} / \mathrm{a} \text { (gauged flow over } \\
\text { Teddington Weir [cumecs]) }\end{array}$ \\
\hline Temperature & n/a (thermometer) \\
\hline Salinity & EPA $600 / 4-79-020$ Method 353.3 \\
\hline Dissolved oxygen & HMSO (1980a) \\
\hline $\mathrm{pH}$ & HMSO (1979) \\
\hline Suspended solids & HMSO (1980b) \\
\hline Total oxidised nitrogen & EPA $600 / 4-79-020$ Method 358.2 \\
\hline Weeks & $\mathrm{n} / \mathrm{a}($ Week $0=\operatorname{Jan} 1,1977)$ \\
\hline $\begin{array}{l}\text { Monthly component } \\
\text { (Jan to Dec) }\end{array}$ & $\begin{array}{l}\text { n/a (instrumental variable, } \\
\text { see text) }\end{array}$ \\
\hline
\end{tabular}

The data sets for 5 decapod crustacean taxa presented by Attrill \& Thomas (1996) were included in this study, namely Carcinus maenas (L.), Liocarcinus holsatus (Fabricus), Crangon crangon (L.), Palaemon serratus (Pennant) and Palaemon longirostris Milne Edwards. These were supplemented by a further data set for Gammarus spp. (Amphipoda). In the field it was not possible to specify the Gammarus spp., although subsampling and subsequent laboratory analysis revealed them to be generally G. zaddachi Sexton with occasional G. salinus Spooner at times of high water or extreme low freshwater flow. The 2 species are regarded as siblings within the $G$. zaddachi complex and are thus genetically extremely closely related, with $G$. zaddachi preferring oligohaline and $G$. salinus mesohaline water (Bulnheim \& Scholl 1981).

Modelling details. Multiple linear regression methods were used to examine the significance of associations between invertebrate abundance and available physico-chemical variables. The models postulate that abundance will be related to the physico-chemical conditions prevailing in the estuary at a given point in time, either because conditions are suited to a particular life-history stage of an organism or because conditions exceed the physiological tolerances of the organism. Accordingly, models of the form

$$
Y_{t}=a_{0}+a_{1} X_{1 t}+a_{2} X_{2 t}+\ldots+a_{k} X_{\mathrm{k} t}+\epsilon_{l}
$$

were estimated where $Y$ represents available invertebrate data at a given point in time $(t), X_{1}$ to $X_{\mathrm{k}}$ are the set of physico-chemical variates that explain $Y$ and $\in$ is a normally distributed error term with zero mean and unit variance (Draper \& Smith 1981).

For statistical analysis, logarithmic (natural) transformations were completed on data, where necessary, to ensure conformance to an approximate normal distribution (Draper \& Smith 1981). To stabilize the variation in the Carcinus maenas data set for use in regression a power transformation (Draper \& Smith 1981) was employed as follows:

$$
W=\left(Y^{\lambda}-1\right) / \lambda
$$

where $Y$ is the original data and $\lambda$ is the power transformation parameter chosen to minimize the F-value connected with the extra sum of squares as recommended by Draper \& Smith (1981). For the model results presented, $\lambda$ was estimated to be 0.30 .

To avoid problems associated with possible spurious correlation, biological rationalizations were used to select an a priori set of feasible variables for inclusion in the multiple regression models. This avoids the post hoc rationalization criticism levelled by many researchers (e.g. Walters \& Collie 1988) against attempts to relate environmental variables to fluctuations in abundance. Furthermore, it requires that ecological theory and observation be used to guide model construction. For example, the use of a special trigger value for Carcinus maenas depends upon laboratory experimentation documenting a threshold for locomotor activity.

From amongst the feasible set of physico-chemical variables, the variables ultimately used in each of the estimated models were selected using forward stepwise regression techniques (Draper \& Smith 1981, Dunn \& Clark 1987). The procedure selects, from among the feasible set, the independent variable with the highest $F$-value and enters it in the model, provided the $F$-value exceeds a pre-specified $F$-to-enter criteria. At successive steps, previously entered regressors are retained in the equation providing their associated $F$ values do not subsequently fail to exceed a pre-specified threshold ( $F$-to-remove). Here the $F$-to-enter and $F$-to-remove values used were at the upper $\alpha=0.05$ point of the $F$-distribution as recommended by Draper \& Smith (1981). Differing F-to-enter and F-to-remove values were used to test the effect of the choice of criteria on the subset of model variables selected and found to have no effect. Instrumental variables were used in the stepwise regression process to capture seasonal influences on fluctuations in crustacean species abundance. Variables representing each month were set equal to 1 if data were collected for that month, zero otherwise (Table 1, Koutsoyiannis 1977)

For Carcinus maenas, an additional instrumental variable (trigger) was defined. As has been previously suggested in the literature (Naylor 1963, Ropes 1968, Atkinson \& Parsons 1973), such a variable may be used to define the temperature threshold below which locomotor activity ceases and sampled abundances may be expected to decline. Threshold values in the range 5 to $11^{\circ} \mathrm{C}$ were examined and an optimal value selected on the basis of $r^{2}$ and minimisation of the regression sum of squares (Draper \& Smith 1981). 
The statistical assumptions which allow the use of least squares estimates include normally distributed residuals, no serial correlation among the residuals and homoscedastic variances. As with any statistical procedure, if the assumptions of the methods are not met, the results of the analysis will not be valid. To ensure that the required statistical assumptions were met, a series of diagnostic tests were applied to all estimated model residuals. These included examining residuals for evidence of non-normality, heteroscedasticity and serial correlation (Draper \& Smith 1981). Royston's extension of the Shapiro-Wilk $W$ statistic (Royston 1982), applicable to sample sizes between 7 and 2000 , was used to judge normality in model residuals. The Shapiro-Wilk statistic and its extensions have been recognized as amongst the most powerful omnibus tests for normality (d'Agostino 1986). Normalized versions of the Royston statistic were computed (Royston 1982) and may be compared to tabular values for the standard normal distribution to determine significance. Values <|1.96| do not produce sufficient evidence to reject the assumption of normality in the residuals at the $\alpha=0.05$ level of significance.

Serial correlation was assessed by computing the sample autocorrelations and comparing computed values to their approximate $95 \%$ confidence intervals to determine significance (Abraham \& Ledolter 1983). Homoscedastic residual variances were confirmed by examining plots of the standardized residuals for evidence of characteristic patterns of increasing or decreasing variance, as recommended by Draper \& Smith (1981).

\section{RESULTS}

\section{Physico-chemical parameters}

The data sets for the 7 physical and chemical parameters incorporated in the crustacean models are represented graphically in Figs. 1 \& 2. Fig. 1 includes the seasonally influenced variables (flow, salinity, temperature) presented by Attrill \& Thomas (1996), with the $x$-axis converted to the time index variable. Four new data sets have been compiled for this paper (suspended solids, $\mathrm{pH}$, dissolved oxygen, total nitrogen; Fig. 2). Of these, oxygen and nitrogen (Fig. 2a,d) demonstrate winter peaks and summer troughs, whilst suspended solids and pH (Fig. 2b,c) are more erratic, responding more to random rainfall and discharge events than to seasonal influences.

\section{Crustacean models}

Of the 6 crustacean taxa included in the study, significant, statistically adequate models were con-
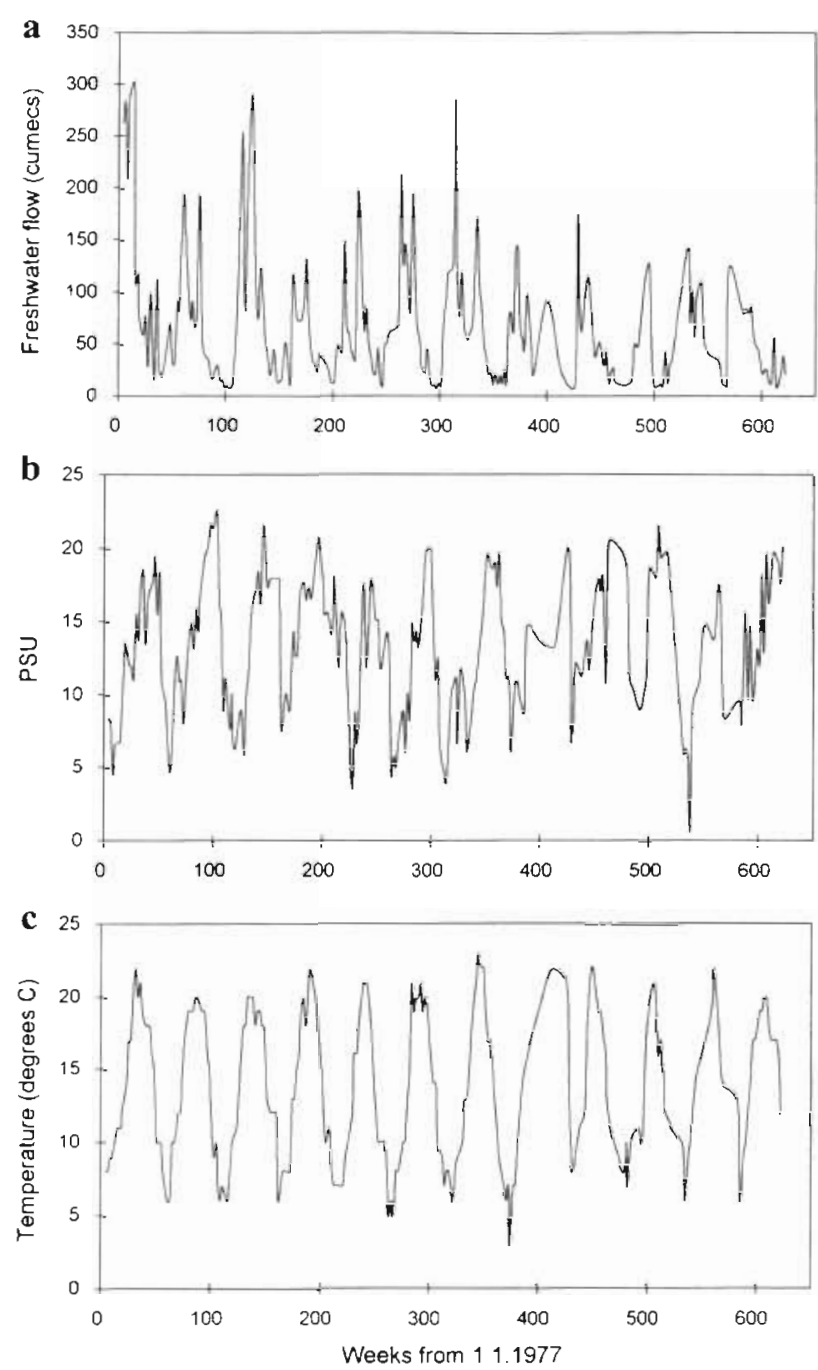

Fig. 1 Physico-chemical variables recorded over the survey period 1977 to 1988 (data from Attrill \& Thomas 1996). (a) Freshwater flow into the estuary from the river Thames, (b) salinity (mid-tide corrected), and (c) water temperature. Variables (b) and (c) recorded from a zone of the Thames estuary bordering West Thurrock power station

structed for 3 of the most abundant species (Carcinus maenas, Crangon crangon, Gammarus spp.). Variables contributing significantly to the explanation of observed variations in taxon abundance, parameter coefficient and standard error estimates, parameter $\mathrm{p}$-values and regression diagnostics are given for each of the modelled species in Tables 2 to 4 . In addition to regression $\mathrm{r}^{2}$ and $F$-statistic values, the Shapiro-Wilk $W$ statistic (SW) and its associated normalised version (NV) are reported in each of the tables. In all cases, parameter estimates are significant at the $\alpha=0.05$ level of significance and resulting models explain greater than $54 \%$ of the observed variation in biota abundance. 

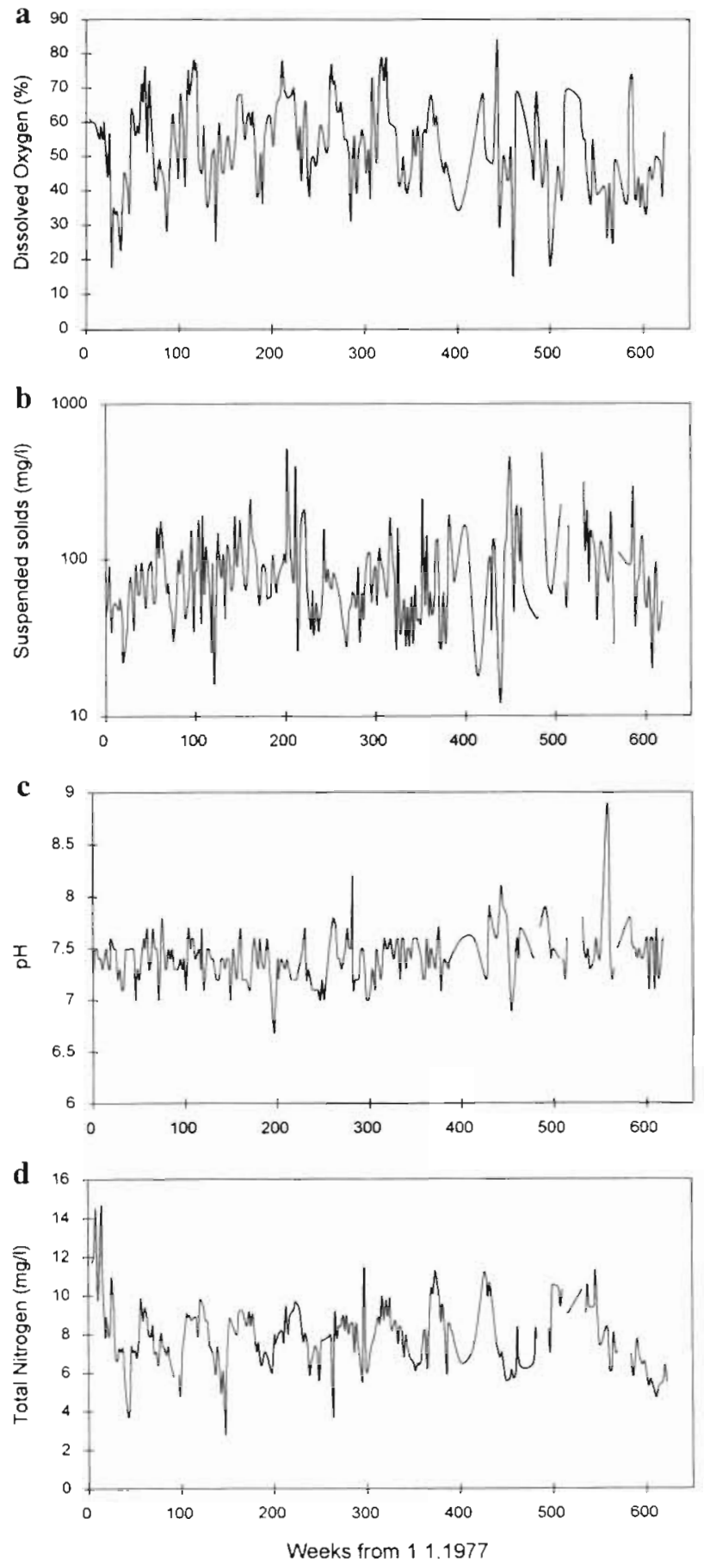

Fig. 2. Physico-chemical variables recorded over the survey period 1977 to 1988 from a zone of the Thames estuary bordering West Thurrock power station. (a) Dissolved oxygen, (b) suspended solids, (c) $\mathrm{pH}$, and (d) total oxidised nitrogen

\section{Significant models}

Carcinus maenas abundance showed a strong seasonal pattern, with negative slope coefficients in late winter (February to March, Table 2) and positive coef-
Table 2. Carcinus maenas abundance results, where the model is in the form natural logarithm C. maenas abundance $=f$ (listed variables) and data were first subjected to a power transformation (see text)

\begin{tabular}{|lccr|}
\hline Variable & Coefficient & SE & p-value \\
\hline Constant & 3.056 & 0.740 & $<0.001$ \\
February & -2.128 & 0.740 & 0.004 \\
March & -2.379 & 0.628 & $<0.001$ \\
August & 2.010 & 0.624 & 0.002 \\
September & 3.021 & 0.604 & $<0.001$ \\
October & 3.843 & 0.589 & $<0.001$ \\
November & 4.326 & 0.594 & $<0.001$ \\
December & 2.646 & 0.706 & $<0.001$ \\
Temperature & 0.114 & 0.052 & 0.031 \\
Trigger & 2.904 & 0.619 & $<0.001$ \\
Weeks & $-4.65 \times 10^{-3}$ & $8.70 \times 10^{-4}$ & $<0.001$ \\
$\mathrm{r}^{2}=0.6152$ & $F=35.49$ & $\mathrm{n}=233$ & \\
Diagnostics: & $\mathrm{SW}=0.9859$ & $\mathrm{NV}=-0.602$ & \\
\hline
\end{tabular}

Table 3. Crangon crangon abundance results, where the model is in the form natural logarithm Crangon abundance $=f$ (listed variables)

\begin{tabular}{|lccc|}
\hline Variable & Coefficient & SE & p-value \\
\hline Constant & 9.150 & 0.624 & $<0.001$ \\
January & -3.407 & 0.492 & $<0.001$ \\
February & -3.869 & 0.509 & $<0.001$ \\
March & -4.216 & 0.446 & $<0.001$ \\
April & -4.412 & 0.395 & $<0.001$ \\
May & -5.308 & 0.455 & $<0.001$ \\
June & -6.654 & 0.413 & $<0.001$ \\
July & -1.943 & 0.411 & $<0.001$ \\
December & -1.429 & 0.480 & 0.003 \\
Oxygen & 0.025 & 0.011 & 0.025 \\
Weeks & -0.0016 & $6.32 \times 10^{-4}$ & 0.014 \\
r $^{2}=0.6661$ & $F=43.19$ & $\mathrm{n}=228$ & \\
Diagnostics: & $\mathrm{SW}=0.9850$ & $\mathrm{NV}=-0.578$ & \\
\hline
\end{tabular}

Table 4. Gammarus spp. abundance results, where the model is in the form natural logarithm Gammarus spp. abundance $=f($ listed variables $)$

\begin{tabular}{|lccr|}
\hline Variable & Coefficient & SE & p-value \\
\hline Constant & 4.642 & 0.443 & $<0.001$ \\
March & 1.277 & 0.401 & 0.002 \\
April & 1.075 & 0.386 & 0.006 \\
July & 1.055 & 0.383 & 0.007 \\
October & -1.487 & 0.462 & 0.002 \\
Salinity & $-2.589 \times 10^{-4}$ & $5.325 \times 10^{-5}$ & $<0.001$ \\
Temperature & 0.258 & 0.029 & $<0.001$ \\
Weeks & -0.0063 & $6.148 \times 10^{-4}$ & $<0.001$ \\
$r^{2}=0.5493$ & $F=33.78$ & $\mathrm{n}=202$ & \\
Diagnostics: & $\mathrm{SW}=0.9868$ & $\mathrm{NV}=-0.851$ & \\
\hline
\end{tabular}




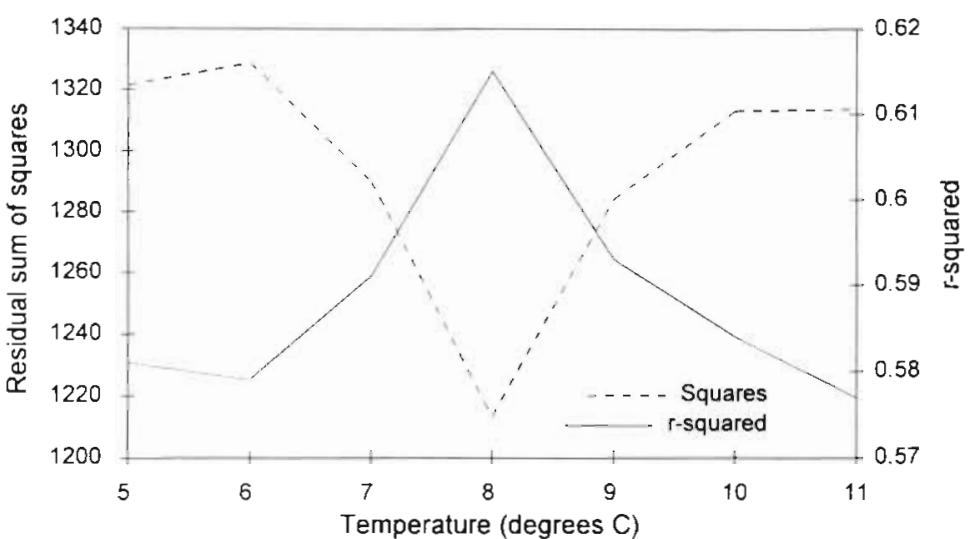

Fig. 3. Regression residual sum of squares ('squares' in figure) and $r^{2}$ value for 'trigger' instrumental variable, where regressions were repeated in $1^{\circ} \mathrm{C}$ increments for trigger temperatures of 5 to $11^{\circ} \mathrm{C}$ ther underscores the significance of temperature as an explanatory variable. Threshold temperatures in the range 7 to $9^{\circ} \mathrm{C}$ proved significant. An optimal value of $8^{\circ} \mathrm{C}$ (Fig. 3) was selected on the basis of the regression residual sum of squares and $\mathrm{r}^{2}$ (Draper \& Smith 1981); Table 2 reports the particulars of model estimation results. Model residuals showed no evidence of serial correlation or heteroscedasticity and were found to be normally distributed ( $\mathrm{SW}=$ 0.9859). The predicted model for C. maenas abundance closely matched the fluctuations in the actual data (Fig. 4a), with only 3 datum points falling outside the $95 \%$ predictive confidence limits for the model (Fig. 4b).

ficients in late summer/autumn (August to December, Table 2). Temperature was the only physico-chemical variable with significant explanatory power $(p<0.05)$. The inclusion of an instrumental variable (trigger) indicating whether the recorded temperature exceeded a possible threshold for $C$. maenas foraging activity fur-
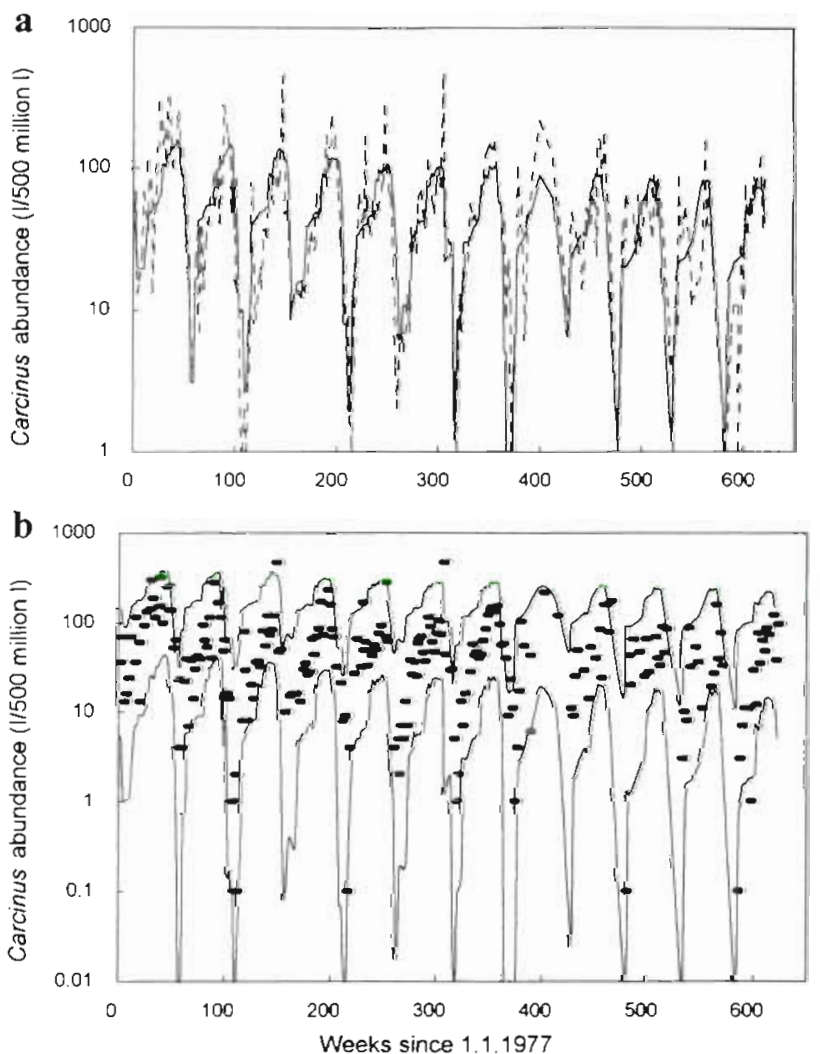

Fig. 4. Carcinus maenas. Plots of the model results for abundance (no. of ind. per 500 million l). (a) Predicted versus actual values for data 1977 to 1988 (solid line $=$ model, broken line $=$ actual values), (b) predictive $95 \%$ confidence limits of model (solid line) with actual values as individual datum points $(-$ )
The brown shrimp Crangon crangon model also had a strong seasonal element, with negative coefficients for the $8 \mathrm{mo}$ period from December to July (Table 3), indicating a continual decrease in the population to a summer minimum. The only seasonally fluctuating physico-chemical parameter found to be significantly
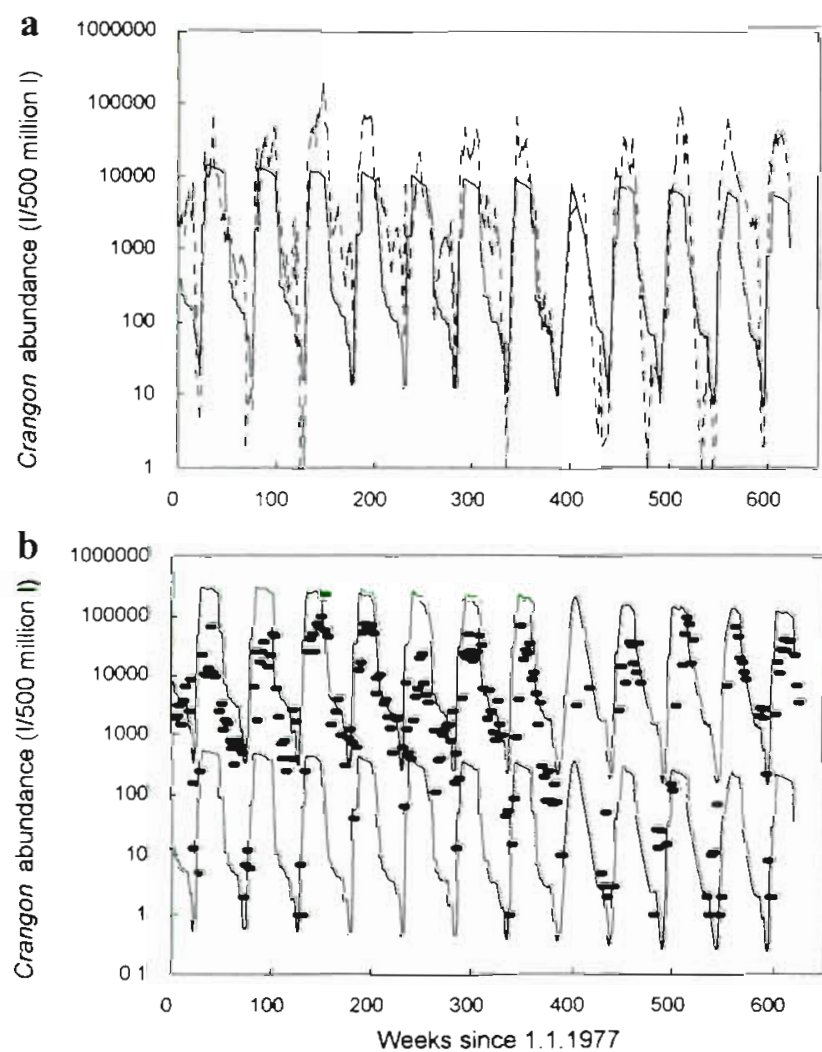

Fig. 5. Crangon crangon. Plots of the model results for abundance. (a) Predicted versus actual values for data 1977 to 1988 (solid line $=$ model, broken line = actual values), (b) predictive $95 \%$ confidence limits of model (solid line) with actual values as individual datum points $[-1$ 
correlated with $C$. crangon abundance was dissolved oxygen. In addition to the positive correlation with dissolved oxygen, a slight, yet significant, temporal trend in C. crangon abundance over the period of the survey was found. Regression diagnostics found no evidence of serial correlation, heteroscedasticity or non-normality in model residuals, thus confirming the statistical adequacy of model estimates. As a result, the fitted model closely followed the observed pattern of annual fluctuations in C. crangon abundance (Fig. 5a). Although the model generally failed to accurately predict the extreme peaks and troughs, this is not an uncommon problem with data series that fluctuate through several orders of magnitude (Law \& Kelton 1991). Nevertheless, the vast majority of the available datum points fell within the $95 \%$ predictive confidence limits for the model (Fig. 5b).
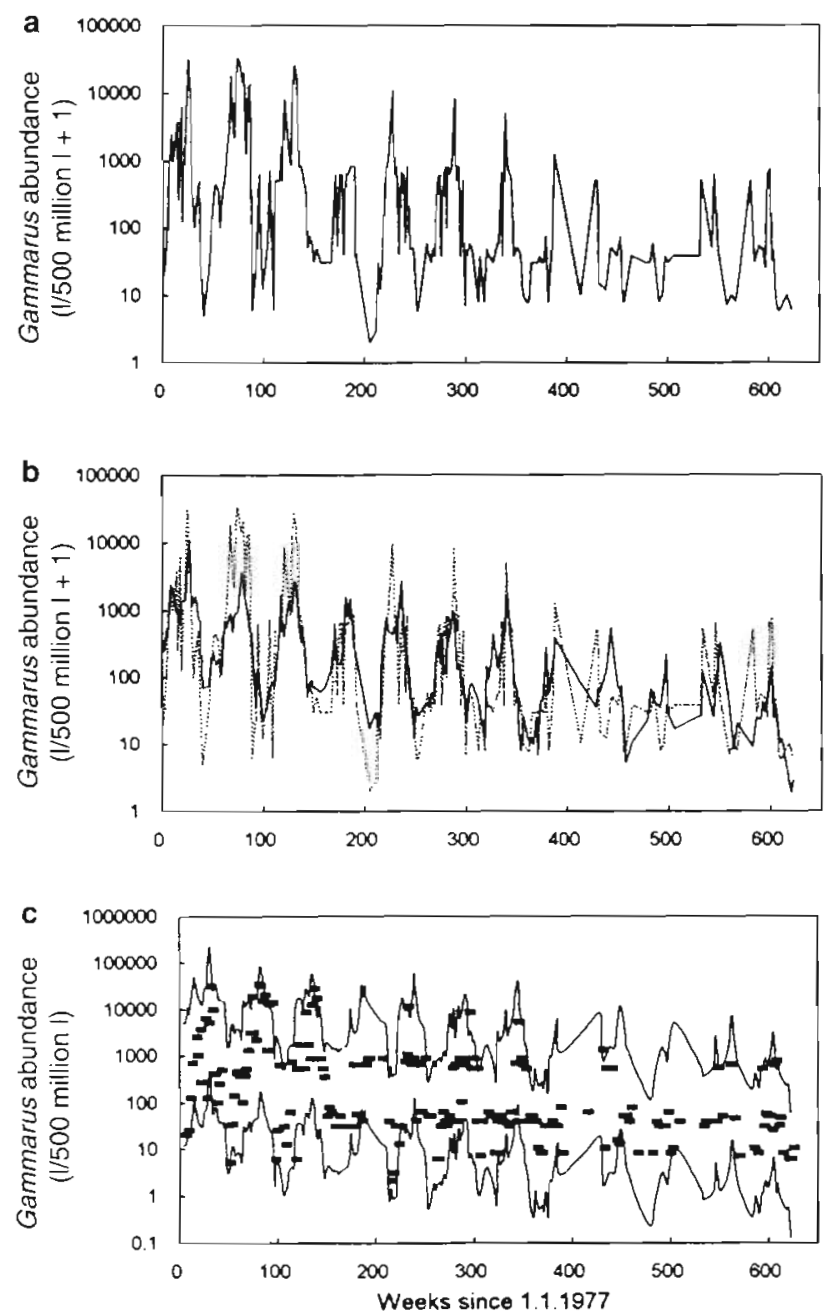

Fig. 6. Gammarus spp. Plots of the model results for abundance. (a) Actual values 1977 to 1988 (previously unreported) (b) predicted versus actual values (solid line $=$ model, broken line $=$ actual values), (c) predictive $95 \%$ confidence limits of model (solid line) with actual values as individual datum points $(\bullet)$
Gammarus spp. abundance displayed a comparatively erratic pulsed distribution over the period of the survey (Fig. 6a), yet a significant model for the data set was constructed using the available physico-chemical data. A seasonal aspect to the distribution was apparent (Table 4), with significant positive coefficients for March, April and July, and a negative coefficient for October. Two environmental variables were included in the model as a result of the strong positive correlation between temperature and Gammarus spp. abundance and the negative correlation between salinity and abundance. Additionally, a significant decrease in the Gammarus spp. population was apparent over the survey period and was reflected in the significance of the temporal trend variable (weeks). Model residuals showed no indication of serial correlation, heteroscedasticity or non-normality, thus confirming the statistical adequacy of the estimated model. The fitted model provided a good prediction of the more erratic seasonal fluctuations in the Gammarus spp. data set (Fig. 6b), particularly the decrease in the maximum values recorded each year. However, the model fell short of predicting zero records (Fig. 6c), although there was a better fit for these minima towards the end of the survey period. Apart from these points, the rest of the data were within the $95 \%$ predictive confidence limits of the model

\section{Insignificant models}

Of the 3 remaining crustacean species Liocarcinus holsatus and Palaemon serratus were recorded only during the summer months, and too infrequently to adequately capture seasonal dynamics ( $L$. holsatus, $\mathrm{n}=47$, $P$. serratus, $\mathrm{n}=30$ ). In addition, all tested models for $P$. longirostris and $P$. serratus yielded non-normal residuals as tested with the normalised version of Royston's extension to the Shapiro-Wilk $W$ statistic. The lack of normality in model residuals resulted in the rejection of all postulated models for describing the observed fluctuations in the abundance of either species on the basis of the statistical inadequacy of the models (Draper \& Smith 1981). Furthermore, no fitted model for $P$. longirostris explained a sufficient amount of the variation in the data (maximum $\mathrm{r}^{2}$ was 0.0431 ), despite an apparent long-term cycle (Attrill \& Thomas 1996).

\section{DISCUSSION}

The construction of the significant models for several estuarine Crustacea provides both supplementary and supportive information on the relationship between these well studied species and their environment. 
Rhythmicity in the distribution of Carcinus maenas has been well studied over tidal (e.g. Dare \& Edwards 1981, Warman et al. 1993), and to a lesser extent seasonal (e.g. Naylor 1962, Hunter \& Naylor 1993) periods. However, these investigations have tended to concentrate on the littoral zone in fully saline conditions, and far fewer studies have addressed patterns of $C$. maenas abundance in estuaries. McGaw \& Naylor (1992) reported that the halokinetic response to reduced salinity previously reported for the species (e.g. Taylor \& Naylor 1977) was virtually absent in estuarine forms. Whilst this conclusion was directed at tidal movement, it could be postulated that any endogenous kinetic response to low salinity would result in crabs being absent from estuarine areas during periods of high flow. This is apparent for the Thames population (negative coefficients for February to March, population displaying a spring minimum abundance), but the model for $C$. maenas did not include a significant salinity parameter, supporting the conclusions of McGaw \& Naylor (1992) and suggesting other environmental cues are more important.

The Carcinus maenas model indicated strong, predictable seasonal components for the abundance pattern of crabs in the Thames, with significant positive coefficients for all months between August and December. Aagaard et al. (1995) recorded peak abundances during late August in a Danish fjord (although large numbers were still apparent in October), whilst very few crabs were caught in February or May, coinciding with the minimum abundance recorded in the Thames. Temperature has been evoked as a possible controlling influence for $C$. maenas population movement (e.g. Naylor et al. 1971, Attrill \& Thomas 1996), and this was the only physico-chemical parameter to feature in the model. The influence of temperature has been suggested to be due mainly to a loss of rhythmic locomotor activity at low temperatures (Naylor 1962). which has resulted in proposals for a threshold temperature below which activity ceases. Ropes (1968) suggested a figure of $7^{\circ} \mathrm{C}$ for C. maenas from the eastern U.S., whilst Atkinson \& Parsons (1973) concluded a common threshold of 'about $8^{\circ} \mathrm{C}$ '. Aagaard et al. (1995), however, noted minimal catches of C. maenas at a temperature of $11.7^{\circ} \mathrm{C}$, but concluded that this was due to a rapid temperature rise from $8^{\circ} \mathrm{C}$ within a week which did not allow crabs to adapt their behaviour. The C. maenas model constructed for the Thames population included the instrumental variable 'trigger' to simulate temperature thresholds for activity and was found to be most significant at $\mathrm{T}=8^{\circ} \mathrm{C}$, thus supporting the conclusions of Atkinson \& Parsons (1973). This temperature threshold therefore appears to be consistent for a range of habitats and geographical areas where C. maenas is found.
The brown shrimp Crangon crangon has a regular, seasonal distribution in the Thames estuary which has been recorded for a range of European systems (Moore et al. 1979, Beukema 1992, Bamber \& Henderson 1994), the shrimps migrating into more saline water during winter and returning up the estuary in summer months. Due to this strong seasonal migration pattern, the previous studies have inferred that $C$. crangon distribution within an estuary is governed by responses to either salinity (e.g. Lloyd \& Yonge 1947, Attrill \& Thomas 1996) and/or temperature (e.g. Verwey 1957, Boddeke 1968). However, these assumptions have not been statistically tested for $C$. crangon abundance, although Henderson \& Holmes (1987) related the distribution of reproductive females to salinity using multiple correlation analysis. C. crangon distribution in the Thames, however, was not significantly related to either temperature or salinity, but did show a positive relationship with dissolved oxygen. This variable was unrecorded in most previous studies, despite the existence of work demonstrating that the shrimps display a strong avoidance behaviour to low oxygen tension (Huddart \& Arthur 1971b, Dyer 1978), resulting in a low abundance of $C$. crangon being associated with conditions of reduced dissolved oxygen. Variation in dissolved oxygen in estuaries is also seasonal (Fig. 2), so it may be the case that $C$. crangon responds over a short time scale to changes in oxygen levels, particularly when hypoxia is associated with low salinity (Hagerman \& Uglow 1982), with salinity being an important controlling factor during reproduction. A significant reduction in the population size of $C$. crangon also was apparent over the survey period. The reasons for this remain unclear as water quality in the Thames continued to improve over the survey period (Kinniburgh 1998) and C. crangon populations have been shown to positively respond to decreases in polluting inputs (Boddeke 1996). However, predation by fish can have a dramatic effect on shrimp populations (Berghahn 1996), so the consequent return of fish species to the Thames following restoration (Thomas 1998) may be having an influence that will require further investigation.

The data set for Gammarus spp. is additional to the species data presented by Attrill \& Thomas (1996) and, like Carcinus maenas and Crangon crangon, demonstrates seasonal patterns in abundance. Although there appears to be more noise in the Gammarus spp. abundance pattern, significant coefficients during spring suggest a regular increase in the population at that time, with a subsequent significant regular decrease during October. G. zaddachi, the dominant species in the Thames estuary (Attrill 1998), has been shown to undertake seasonal reproductive migrations (Dennert et al. 1969, Girish et al. 1974, Hough \& Nay- 
lor 1992), the population moving seawards during spring/summer. The peak in abundance recorded at West Thurrock is therefore likely to represent $G$. $z a d$ dachi moving into this part of the estuary to reproduce, returning upstream again in autumn. Hough \& Naylor (1992) reported the seaward areas of the Conway Estuary (N. Wales) were depopulated in winter; this trend is also apparent in the Thames. Previous studies have linked the seasonal migrations of $G$. zaddachi to both salinity (e.g. Hough \& Naylor 1992) and temperature (Dennert \& van Maren 1974), the species being able to tolerate low salinities at low temperature, but migrating downstream to reproduce during periods of higher temperature. Both of these variables were significant components within the model for the Thames population, indicating their importance as controlling factors for the species. The temporal trend for Gammarus spp. demonstrated a significant reduction in the size of the population. As for C. crangon, predation by fish may be an explanation as it is probably the single most important prey species for the majority of fish species (Wheeler 1969), but a notable upstream extension of $G$. zaddachi has been noted in the upper, freshwater part of the Thames estuary (Andrews 1977, Attrill 1998) the species replacing $G$. pulex in the tidal freshwater reaches. It is therefore possible that the whole population has demonstrated an upstream movement, the decrease in abundance at West Thurrock relating to fewer individuals in that part of the estuary rather than any reduction in total population size.

It was not possible to construct a significant model for Palaemon longirostris, but this negative result is interesting as previous work has suggested strong seasonal migrations related to annual patterns of salinity (e.g. Van den Brink \& Van der Velde 1986, Cartaxana 1994), although such conclusions were observational and not tested statistically

The results of this study have indicated the value of statistically relating the pattern of changes in a larger suite of estuarine environmental parameters to indices of biotic abundance. In addition, results suggest that assumptions concerning the strength of the relationships between organisms and easily measured abiotic parameters, such as salinity and temperature, may require validation. Out of the 4 large species data sets analysed for the Thames estuary, 2 demonstrated a significant relationship with temperature and 1 with salinity over the 12 yr period of study. Salinity has long been regarded as the most important controlling factor for estuarine organisms, particularly those that demonstrate strong seasonal patterns. The true case could be more subtle than this, with populations of estuarine organisms responding to other environmental cues, such as temperature and dissolved oxygen. These variables often demonstrate seasonal patterns which may be ignored due to assumptions about relationships between species abundance and salinity. Furthermore, the prevalence of seasonality in many of the abiotic parameters raises the possibility of measures, like salinity, being correlated with abundance through a common third variable. Only when a sufficiently large suite of physico-chemical parameters are measured can a clear picture of the role of any single abiotic variable in influencing observed abundance patterns be developed. Clearly further work needs to be done and, in the meantime, researchers should treat assumptions about the influence of any single abiotic variable with care.

Acknowledgements. The authors thank the Environment Agency for permission to analyse and publish the data. Support for completion of the work was provided by a NATO Collaborative Research Grant (CRG 960577) to M.J.A. and M.P., an NSERC Research Grant to M.P. and a British Council Grant. Opinions stated in the paper are those of the authors and do not necessarily reflect those of any supporting agency or group.

\section{LITERATURE CITED}

Aagaard A, Warman CG, Depledge MH (1995) Tidal and seasonal changes in the temporal and spatial distribution of foraging Carcinus maenas in the weakly tidal littoral zone of Kerteminde Fjord, Denmark. Mar Ecol Prog Ser 122: $165-172$

Abraham B, Ledolter J (1983) Statistical methods for forecasting. John Wiley and Sons. New York

Andrews MJ (1977) Observations on the fauna of the metropolitan River Thames during the drought in 1976. Lond Nat 56:44-56

Andrews MJ, Rickard DG (1980) Rehabilitation of the inner Thames Estuary. Mar Pollut Bull 11:327-332

Atkinson RJA, Parsons AJ (1973) Seasonal patterns of migration and locomotor rhythmicity in populations of Carcinus. Neth J Sea Res 7:81-93

Attrill MJ (1998) The benthic macroinvertebrate communities of the Thames estuary. In: Attrill MJ (ed) A rehabilitated estuarine ecosystem. The environment and ecology of the Thames Estuary. Kluwer Academic Publishers, Dordrecht, p $85-114$

Attrill MJ, Thomas RM (1996) Long-term distributicn patterns of mobile estuarine invertebrates (Ctenophora, Cnidaria, Crustacea: Decapoda) in relation to hydrological parameters. Mar Ecol Prog Ser 143:25-36

Attrill MJ, Rundle SD. Thomas RM (1996) The influence of drought-induced low freshwater flow on an upper-estuarine macroinvertebrate community. Water Res 30:261-268

Bamber RN, Henderson PA (1994) Seasonality of caridean decapod and mysid distribution and movements within the Severn estuary and Bristol channel. Biol J Linn Soc 51. $83-91$

Berghahn R (1996) Episodic mass invasions of juvenile gadoids into the Wadden sea and their consequences for the population dynamics of brown shrimp (Crangon crangon). PSZN I: Mar Ecol 17:251-260

Beukema JJ (1992) Dynamics of juvenile shrimp Crangon 
crangon in a tidal-flat nursery of the Wadden Sea after mild and cold winters. Mar Ecol Prog Ser 83:157-165

Boddeke R (1968) Forecasting the landings of brown shrimps (Crangon crangon) in the Netherlands. ICES Shellfish \& Benthos Committee Vol 8, ICES, Copenhagen

Boddeke R (1996) Changes in the brown shrimp (Crangon crangon L.) population off the Dutch coast in relation to fisheries and phosphate discharge. ICES J Mar Sci 53 995-1002

Bourcier M (1996) Long-term changes (1954 to 1982) in the benthic macrofauna under the combined effects of anthropogenic and climatic action (example of one Mediterranean Bay). Oceanol Acta 19:67-78

Buchanan JB, Moore, JJ (1986) Long-term studies at a benthic station off the coast of Northumberland. Hydrobiologia 142:121-127

Bulnheim HP, Scholl A (1981) Electrophoretic approach to the biochemical systematics of gammarids. Helgol Meersunters 34:391-400

Callaghan JT (1984) Long-term ecological research. BioSci 34:363-367

Cartaxana A (1994) Distribution and migrations of the prawn Palaemon longirostris in the Mira River estuary (SW Portugal). Estuaries 17:685-694

Champely S, Doledec S (1997) How to separate long-term trends from periodic variation in water quality monitoring Water Res 31:2849-2857

Coull BC (1986) Long-term variability of meiobenthos: value, synopsis, hypothesis generation and predictive modelling. Hydrobiologia 142:271-279

d'Agostino RB (1986) Test for the normal distribution. In: d'Agostino RB, Stephens MA (eds) Goodness-of-fit techniques. Marcel Dekker, New York, p 367-419

Dare PJ, Edwards RL (1981) Underwater television observations of the intertidal movements of shore crabs, Carcinus maenas, across a mudflat. J Mar Biol Assoc UK 61:107-116

Dennert HG van Maren MJ (1974) Further observations on the migration of Gammarus zaddachi Sexton (Crustacea, Amphipoda) in a French stream. Bull Zool Mus Univ Amsterdam 3:157-167

Dennert HG, Dennert AL, Kant P, Pinkster S, Stock JH (1969) Upstream and downstream migrations in relation to the reproductive cycle and to environmental factors in the amphipod Gammarus zaddachi. Bijdr Dierk 39:11-43

Draper NR, Smith H (1981) Applied regression analysis, 2nd edn. John Wiley and Sons, New York

Dunn OJ, Clark VA (1987) Applied statistics: analysis of variance and regression, 2nd edn. John Wiley and Sons, New York

Dyer MF (1978) Studies of the cardiac and ventilatory behaviour of the brown shrimp Crangon crangon (L.). PhD thesis, University of Hull

Girish HB, Dieleman JC, Petersen GW, Pinkster S (1974) The migration of two sympatric gammarid species in a French estuary. Bijdr Dierk 44:239-273

Gray JS, Christe H (1983) Predicting long-term changes in marine benthic communities. Mar Ecol Prog Ser 13:87-94

Hagerman L. Uglow RF (1982) Effects of hypoxia on osmotic and ionic regulation in the brown shrimp Crangon crangon (L.) from brackish water. J Exp Mar Biol Ecol 63:93-104

Henderson PA, Holmes RHA (1987) On the population biology of the common shrimp Crangon crangon (L.) (Crustacea: Caridea) in the Severn estuary and Bristol Channel. J Mar Biol Assoc UK 67:825-847

HMSO (1979) The measurement of electrical conductivity and the laboratory determination of the $\mathrm{pH}$ value of natural, treated and waste waters, 1978. HMSO, London
HMSO (1980a) Dissolved oxygen in natural and waste waters, 1979 version: two methods. HMSO, London

HMSO (1980b) Suspended, settleable and total dissolved solids in waters and effluents. HMSO, London

Hough AR, Naylor E (1992) Biological and physical aspects of migration in the estuarine amphipod Gammarus zaddachi. Mar Biol 112:437-443

Huddart R, Arthur DR (1971a) Shrimps and whitebait in the polluted Thames estuary. Int J Environ Stud 2:21-34

Huddart R, Arthur DR (1971b) Shrimps in relation to oxygen depletion and its ecological significance in a polluted estuary. Environ Pollut 2:13-35

Hunter E, Naylor E (1993) Intertidal migration by the shore crab Carcinus maenas. Mar Ecol Prog Ser 101:131-138

Jassby AD, Powell TM (1990) Detecting changes in ecological time series. Ecology 71:2044-2052

Kinniburgh J (1998) Physical and chemical characteristics. In: Attrill MJ (ed) A rehabilitated estuarine ecosystem. The environment and ecology of the Thames Estuary. Kluwer Academic Publishers, Dordrecht, p 27-48

Koutsoyiannis A (1977) Theory of econometrics, 2nd. Macmillan Press, London

Law AM, Kelton WD (1991) Simulation modeling and analysis, 2nd edn. McGraw-Hill, New York

Lloyd AJ, Young CM (1947) The biology of Crangon vulgaris $\mathrm{L}$. in the Bristol Channel and Severn estuary. J Mar Biol Assoc UK 26:626-661

López-Jamar E, Francesch O, Dorrio AV, Parra S (1995) Longterm variation of the infaunal benthos of $\mathrm{La}$ Coruna Bay (NW Spain): results from a 12-year study $(1982-1993)$. Sci Mar 59 (Suppl 1):49-61

McGaw IJ, Naylor E (1992) Distribution and rhythmic locomotor patterns of estuarine and open-shore populations of Carcinus maenas. J Mar Biol Assoc UK 72:599-609

Moore JW, Moore IA, Claridge PN (1979) Seasonal changes in density, composition and reproductive biology of crustacean populations in the Severn estuary. Crustaceana 36: $113-122$

Naylor E (1962) Seasonal changes in a population of Carcinus maenas (L.) in the littoral zone. J Anim Ecol 31:601-609

Naylor E (1963) Temperature relationships of the locomotor rhythm of Carcinus. J Exp Biol 40:669-679

Naylor E, Atkinson RJA, Williams BG (1971) External factors influencing the tidal rhythm of shore crabs. J Interdiscip Cycle Res 2:173-180

Pearson TH (1975) The benthic ecology of Loch Linnhe and Loch Eil, a sea-loch system on the west coast of Scotland. IV. Changes in the benthic fauna attributable to organic enrichment. J Exp Mar Biol Ecol 20:1-41

Pearson TH (1982) The Loch Eil project: population fluctuations in the macrobenthos. J Exp Mar Biol Ecol 56:305-321

Power M (1997) Assessing the effects of environmental stressors on fish populations. Aquat Toxicol 39:151-169

Power M, Attrill MJ, Thomas RM (1999) Heavy metal concentration trends in the Thames Estuary. Water Res 33: $1672-1680$

Rhoads DC, Germano JD (1986) Interpreting long-term changes in benthic community structure: a new protocol. Hydrobiologia 142:291-308

Ropes JW (1968) The feeding habits of the green crab Carcinus maenas (L.). Fish Bull Fish Wildl Serv US 67 : 183-203

Royston JP (1982) An extension of Shapiro and Wilk's W test for normality to large samples. Appl Stat 31:115-124

Taylor AC, Naylor E (1977) Entrainment of the locomotor rhythm of Carcinus by cycles of salinity change. J Mar Biol Assoc UK 57:273-277 
Thomas RM (1998) Temporal changes in the movements and abundance of Thames Estuary fish populations. In: Attrill MJ (ed) A rehabilitated estuarine ecosystem. The environment and ecology of the Thames Estuary. Kluwer Academic Publishers, Dordrecht, p 115-140

Van den Brink FWB, Van der Velde G (1986) Observations on the population dynamics and distribution of the white prawn Palaemon longirostris $\mathrm{H}$. Milne Edwards (Crustacea, Decapoda, Natantia) in the Netherlands, with special reference to its occurrence in the major rivers. Arch Hydrobiol 107:465-495

Verwey $J$ (1957) A plea for the study of temperature influence on osmotic regulation. Année Biol 33:129-49

Walters CJ, Collie JS (1988) Is research on environmental fac-

Editorial responsibility: John Gray (Contributing Editor),

Oslo, Norway tors useful to fisheries management? Can J Fish Aquat Sci $45: 1848-1854$

Warman CG, Reid DG, Naylor E (1993) Variation in the tidal migratory behaviour and rhythmic light-responsiveness in the shore crab. Carcinus maenas. J Mar Biol Assoc UK 73: $355-364$

Wei WWS (1990) Time series analysis: univariate and multivariate methods. Addison-Wesley, New York

Wheeler A (1969) The fishes of the British Isles and north west Europe. MacMillan, London

Wolfe DA, Champ MA, Flemer DA, Mearns AJ (1987) Longterm biological data sets: their role in research, monitoring and management of estuarine and coastal marine systems Estuaries 10:181-193

Submitted: April 25, 1998; Accepted: November 4, 1998 Proofs received from author(s): February 26, 1999 